\title{
Recorregut de recerca geològica i mineralògica per les comarques del Baix Ebre i del Baix Maestrat: des del Mont caro a Fredes i al Castell de Cabres
}

Josep Maria Mata-Perelló

Joaquim Sanz Balagué

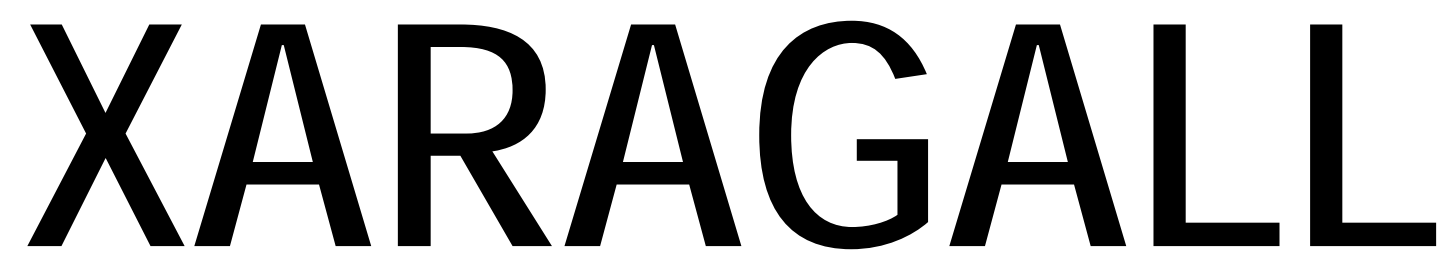

REVISTA DE CIÈNCIES DE LA CATALUNYA CENTRAL

\section{n. 3}

MARÇ 2015 


\title{
RECORREGUT DE RECERCA GEOLÒGICA I MINERALÒGICA PER LES COMARQUES DEL BAIX EBRE I DEL BAIX MAESTRAT: DES DEL MONT CARO A FREDES I AL CASTELL DE CABRES
}

\author{
Josep Maria Mata-Perelló \\ Museu de geologia Valentí Masachs, Escola Politècnica Superior d'Enginyeria de Manresa \\ (EPSEM), Universitat Politècnica de Catalunya · BarcelonaTech (UPC), 08272 Manresa, Spain
}

\section{Joaquim Sanz Balagué}

Departament d'Enginyeria Minera i Recursos Naturals (EMRN), Escola Politècnica Superior d'Enginyeria de Manresa (EPSEM), Universitat Politècnica de Catalunya . BarcelonaTech (UPC), 08272 Manresa, Spain

Paraules clau: Sistema Mediterrani, Patrimoni miner

\section{Resum}

Itinerari realitzat el 13 d'abril de 2014. En aquesta ocasió, el recorregut de l'itinerari discorrerà, en la seva totalitat pel Sistema Mediterrani, tot i que dintre de la denominada Zona d'Enllaç, pels seus indrets meridionals; i més exactament per la Serralada Prelitoral Catalana, concretament pel Mont Caro.

Així, l'itinerari discorrerà en la seva major part entorn a la denominada Falla del Baix Ebre, tant pel bloc esfondrat (per la Depressió del Baix Ebre), com per I'aixecat (pels Ports de Tortosa). Així, el recorregut s'iniciarà a la primera sotsunitat esmentada, per la qual es transitarà breument, fins iniciar I'ascens cap al Mont-Caro. Posteriorment, s'endinsarà dintre de la Zona $d^{\prime} E n l l a c ̧$, en fer el recorregut cap a Fredes i sobretot cap el Castell de Cabres.

Per altra banda, el recorregut transitarà quasi íntegrament per la Regió de Tortosa (per la comarca del Baix Ebre), una de les quatre que constitueixen aquesta demarcació, també coneguda sovint amb el nom genèric de les Terres de l'Ebre. I també ho farà per la denominada Regió de Castelló, concretament per la comarca de l'Alt Maestrat. 


\section{Objectius fonamentals}

A través d'aquest itinerari, i d'acord amb el sentit de la marxa del mateix, s'intentaran aconseguir els següents objectius:

1. Estudi i observació dels materials mesozoics (representat per tots els seus trams, pel Triàsic, del Juràssic i del Cretàcic, i en especial pels dos darrers, segons els indrets) els quals formen part de la Serralada Prelitoral Catalana, i més concretament dels relleus dels Ports de Tortosa i dels Ports de Beseit. Tot i així, en els primers trams aquest recorregut sols trobarem afloraments dels materials carbonatats juràssics, del Dogger i del Liàsic. (Aquests materials els trobarem a diferents indrets del recorregut de l'itinerari entre el Mont Caro i les immediacions de Fredes). Tot i així, pels darrers trams del recorregut, prop de la darrera població esmentada, anirem trobant afloraments dels materials carbonatats del Cretàcic Inferior i Mig.

2. Observació de l'estructura de les unitats geològiques anteriorment esmentades. En especial de la Depressió del Baix Ebre i de la Serralada Prelitoral Catalana (pels indrets corresponents als Ports de Tortosa). I tanmateix, observació a gran escala de la Falla del Baix Ebre, a través del denominat Graó de Tortosa - Onda

3. Estudi, si s'escau, d'algunes mineralitzacions situades entre els materials mesozoics de la Serralada Prelitoral Catalana. Entre aquestes, farem esment de les mineralitzacions ferruginoses associada a "hard-grounds" $i$ a laterites, localitzada prop de la població de Fredes ubicades entre els materials carbonatats del Juràssic Mig.

4. Observació de diferents explotacions que anirem trobant al llarg del recorregut de I'itinerari.

5. Observació de l'impacte produït sobre el Medi Natural, a partir de les explotacions anteriors.

6. Observació, si s'escau, de les tasques de restauració mediambiental realitzades a les explotacions anteriors, per tal de reduir l'impacte produït sobre el Medi natural.

7. Observació i valorització de diferents aspectes relacionats amb el Patrimoni Geològic $i$ Miner. 


\section{Antecedents}

No tenim coneixement de cap antecedent bibliogràfic, en relació amb el recorregut d'aquest itinerari, ni de caire total (relatiu a tot l'itinerari), ni de caire parcial. Solament farem esment de dos treballs nostres (Mata Perelló 2006a, 2006b i 2011), els quals discorren per uns recorreguts parcialment coincidents amb el present, especialment pels trams entre Fredes i Castell de Cabres. Hi ha un altre antecedent molt recent: Mata Perelló (2014), relatiu al recorregut pels voltants del Caro, exclusivament.

Pel que fa a l'estructura geològica dels indrets pels quals discorrerà el recorregut de l'itinerari, farem esment de dos treballs generals, relatius al conjunt dels Països Catalans: Guimerà et altri (1992), i Riba et altri (1976). També farem esment de les publicacions de l'IGME (1973 i 1979), relatius a les contrades per les quals discorre aquest itinerari.

Pel que fa a l'estudi de les mineralitzacions situades al llarg del recorregut, farem un especial esment d'un altre treball nostre, relatiu al conjunt de les mineralitzacions situades arreu de Catalunya. Es tracta del treball de Mata Perelló (1991).

Tots aquests treballs esmentats, figuraran per ordre alfabètic a l'apartat dedicat a les REFERĖNCIES BIBLIOGRÀFIQUES, al qual ens remetem.

\section{Recorregut de l'itinerari}

El recorregut d'aquest itinerari començarà al cim del Mont-Caro, realitzant-se diferents aturades pel seu voltant, baixant poc a poc cap a la base d'aquesta muntanya (la més alta de la comarca del Baix Ebre).

Posteriorment, el recorregut es dirigirà per una pista en molt irregular estat de conservació (normalment molt dolenta, ja que travessa diferents barrancades). Aquest camí se' $n$ va sempre cap a ponent, cap a la localitat de Fredes. En aquest tram, es faran diverses aturades.

Després, el recorregut (ja dintre del Baix Maestrat i en concret per la Tinença de Benifassà) el recorregut es dirigirà cap a les immediacions de les poblacions del Bellestar i de la Pobla de Benifassà. Tot i així, el recorregut s'encaminarà cap el Boixar i cap a Castell de Cabres, per on finalitzarà. 


\section{Advertiments previs}

Com en altres recorreguts de RECERCA GEOLÒGICA I MINERALÒGICA ..., si es disposa del temps suficient, poden efectuar-se passant per totes les parades i filloles. En cas contrari, recomanem reestructurar el recorregut, prescindint de les anomenades PARADES CONDICIONALS, i d'altres si s'escau.

També recomanem de cercar la informació més adient, sobre els trams a recórrer mitjançant camins de terra, o de pista. Tot i així, per efectuar bona part d'aquest recorregut (concretament pel tram entre les immediacions del Caro i les de Fredes) cal fer-ho per camins en no gaire bones condicions. El millor es fer-ho amb vehicles preparats, molt millor en vehicles $4 \times 4$.

Per altra banda, recomanem tenir una cura extrema de la NATURA, evitant qualsevol forma d'agressió sobre ella, o de fer-n'hi un mal ús del que en ofereix la nostra mare Terra.

\section{Descripció de l'itinerari}

Com en altres itineraris, a continuació veurem una sèrie de "parades o estacions". En cada una d'elles es farà un breu comentari. Per d'altra banda, darrera del nom de l'indret (o de la parada), situarem entre parèntesi el número del Mapa Topogràfic, a escala 1:50.000, on es troba l'indret de l'aturada.

En aquesta ocasió, utilitzarem els dos següents fulls de l'esmentat mapa topogràfic, editat per I'Instituto Geográfico y Catastral": concretament dels següents: 520 (o de Peñarroya de Tastavins / Penarroja de Tastavins) i 521 (també dit de Beceite / Beseit).

Així doncs, la relació ordenada, de les parades que composen el recorregut d’aquest itinerari. és la següent:

\subsection{Parada 1. CIM DEL MONT-CARO, (terme municipal de Roquetes, comarca del Baix Ebre). (Full 521).}

El recorregut d'aquest itinerari el començarem per les immediacions del cim del Mont-Caro. Cal dir que aquest indret (de 1.442 metres) constitueix el sostre de la comarca del Baix Ebre.

En aquest indret hi ha un important gruix de sediments carbonatats, mesozoics, els quals pertanyen al Juràssic. Aquests materials són eminentment calcaris (sovint també són dolomítics) i pertanyen al Dogger, al Juràssic Per d'altra banda, aquests materials es situen dintre de la Serralada Prelitoral Catalana. Tot i que es troben dintre de la denominada Zona d'Enllaç amb el Sistema Ibèric.

Des d'aquest indret, força enlairat, es pot gaudir d'un bon lloc d'observació, tant de la Serralada Prelitoral Catalana (a traves de les seves sotsunitats) com de la llunyana Depressió Geològica de l'Ebre. Tanmateix es fa força palès el Delta de l'Ebre. (fotografia 1). 


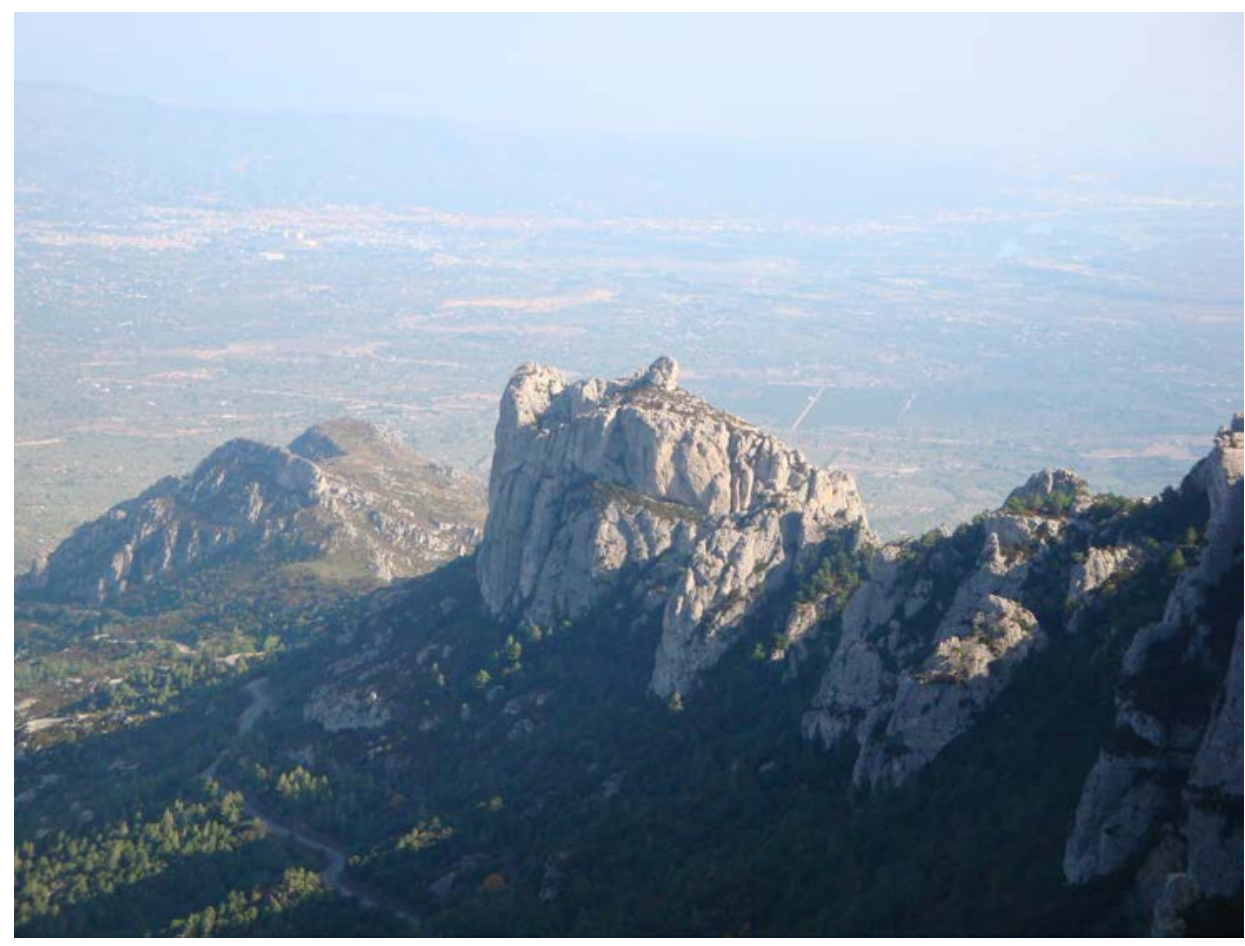

Fotografia 1. Un aspecte del Baix Ebre, des del Mont Caro

\subsection{Parada 2. CARRETERA AL MONT-CARO, A UNS 0’9 Km DEL CIM, (terme municipal de Tortosa, comarca del Baix Ebre). (Full 521).}

Des de la parada anterior, cal ara baixar cap a la base del cim del Mont-Caro, anant cap a la bifurcació amb el camí de Fredes. Així, a poc menys de 1 Km del Cim (a 0’9 Km), farem una nova aturada.

En aquest recorregut s' han continuat fent palesos els materials carbonatats esmentats a les parada anteriors. Aquests materials es troben força replegats. Per d'altra banda també estan força carstificats. Aquests materials pertanyen al Juràssic i més concretament ara al Dogger, com ja hem dit a l'aturada anterior.

En aquest indret es fa palesa una cova, desenvolupada entre dues fractures que tallen als materials carbonatats mesozoics, que aquí presenten un caràcter clarament calcari. 


\subsection{Parada 3. IMMEDIACIONS DE LA PEIRA I DEL MASCAR, PROP DE LA CRUÏLLA AMB EL CAMÍ DE FREDES, (terme municipal de Tortosa, comarca del Baix Ebre). (Full 521).}

Després de realitzar la parada anterior, cal acabar de baixar, fins arribar a les immediacions de la cruïlla amb el camí que es dirigeix per l'esquerra, cap a Fredes (i també cap a Beseit), tot baixant del cim Mont-Caro. En aquest indret, farem una nova aturada, a uns 0’7 Km de l'anterior.

En aquest recorregut, hem continuat trobant els materials esmentats a les parades anteriors (concretament, els nivells carbonatats del Dogger). Tot i així, ara veiem uns afloraments dels materials carbonatats del nivells inferiors del Dogger i fins i tot del Liàsic. Aquests materials es troben aquí força fracturats. Per d'altra banda, en aquest recorregut, hem arribat molt propers a l'encavalcament del Mascar, de direcció clarament “catalana”; és a dir NE - SW.

Així, a la vora de la carretera, just després d'unes fortes corbes es fan força paleses aquestes falles. Un esquema d'aquestes falles és el següent. (esquema 1).



Esquema 1 


\subsection{Parada 4. COLL DE LA CARRASQUETA, CAMÍ DEL CARO A FREDES I A BESEIT, (terme municipal de Roquetes, comarca del Baix Ebre). (Full 521)}

Després de realitzar l'aturada anterior, cal agafar el camí que es dirigeix cap a ponent, cap a Fredes (i també cap a Beseit). Després de passar el paratge del Mascar, arribarem al Coll de la Carrasqueta. Per les seves immediacions farem una nova aturada, a poc més de $2 \mathrm{Km}$ de la parada anterior.

En aquest recorregut, hem trobat inicialment afloraments dels nivells carbonatats juràssics dels nivells inferiors del Dogger; i també del Liàsic. Tot i així, ara hem travessat l'encavalcament del Mascar i trobem uns afloraments carbonatats, també del Dogger, però dels trams superiors del mateix. En aquest encavalcament, el primers es posen sobre els segons. Aquest encavalcament és clarament "català" i presenta un arrumbament NE - SW (en ocasions també ENE - WSW).

Així, ara es fan palesos per arreu els afloraments dels materials carbonatats del Dogger Superior, amb trams fonamentalment calcaris. Aquests materials es situen dintre de la Serralada Prelitoral Catalana, a la seva zona d'Enllaç amb el Sistema Ibèric.

\subsection{Parada 5. IMMEDIACIONS DEL VALL DE CARLARES, CAMÍ DEL CARO A FREDES I A BESEIT, (terme municipal de Tortosa, comarca del Baix Ebre). (Full 521)}

Després de realitzar l'aturada anterior, cal agafar el camí que es dirigeix cap a ponent. En arribar a la denominada Vall de Carlares, farem una nova aturada. Així, des de I'anterior, haurem efectuat un recorregut molt proper als $8 \mathrm{~km}$, aproximadament, per tal d'arribar fins aquest indret.

En aquest recorregut, hem anat trobant afloraments del Juràssic en tot aquest trajecte. Fonamentalment, es tracta de nivells carbonatats (calcaris i dolomítics) que pertanyen als nivells superiors del Dogger.

Per altra banda, en aquest tram haurem trobat indrets espectaculars. Així, prop d'on ara som es troben les conegudes Gúbies del Regatxol, que constitueixen part de la capçalera del riu Ulldemó. Així bona part de les aigües es dirigeixen cap el Nord, cap a Beseit, fonamentalment.

\subsection{Parada 6. IMMEDIACIONS DE LA FONT DE LES BASSETES, CAMÍ DEL CARO A FREDES I A BESEIT, (terme municipal de la Sènia, comarca del Montsià). (Full 521)}

Després de realitzar l'aturada anterior, cal continuar pel camí que es va dirigint cap a ponent (cap a Fredes i cap Beseit). En arribar a les immediacions de la Font de les Bassetes farem una nova aturada, a uns $6 \mathrm{Km}$ de l'anterior.

En bona part d'aquest recorregut, haurem trobat afloraments dels materials esmentats a I'aturada anterior. Així, per arreu, haurem vist afloraments dels materials carbonatats del Dogger, dels seus nivells superiors.

Tot i així, en aquest indret veiem un interessant encavalcament d'aquests materials sobre els cenozoics de l'Eocè (els quals pertanyen a la Depressió Geològica de l'Ebre, tot i que es troben coberts cap el Nord per diverses làmines d'encavalcament). Així, ara, haurem tornat a travessar l'Encavalcament de Mascar, molt a ponent d'on ens trobàvem abans. 
Per altra banda, en aquest recorregut, hem tornat a trobar indrets espectaculars, com el Tossal de I'Espada o com el Barranc de Millers (afluent del riu Matarranya), per on hem pujat cap a la Font del Teix i cap on som ara. Precisament, en aquest tram, el camí ha estat força dolent.

\subsection{Parada 7. EL PINAR PLA, (antic terme municipal de Fredes, actualment del de la Pobla de Benifassà, comarca del Baix Maestrat). (full 521)}

Després de fer l'aturada anterior, cal continuar cap a ponent, anant sempre cap a Fredes i també cap a Beseit. En aquest recorregut, després de passar pel paratge de Rafalgari, aviat s'arribarà a l'indret del Pinar Pla, per on farem una nova aturada, a uns $6 \mathrm{Km}$, aproximadament de l'anterior.

En aquest recorregut, hem trobat inicialment els materials que hem esmentat a l'aturada anterior: els nivells de lutites, calcolutites, gresos i conglomerats (segons els indrets) de l'Eocè. Després, haurem vist nivells de roques carbonatades del Cretàcic Inferior (fonamentalment de I'Aptià), discordants amb els anteriors. Tots aquests materials han estat encavalcats pels materials Juràssics que hem vist a l'aturada anterior. Al respecte d'aquest encavalcament, cal dir que va variant de direcció, passant d'una direcció clarament "catalana" a una direcció més "ibèrica", de NE - SW a E - W i fins i tot a WNW - ESE (més al Nord i més a ponent d'on ara som).

Així, ara en aquest indret, es fan palesos uns afloraments dels materials basals del Cretàcic, concretament del Barremià. Aquests materials són eminentment carbonatat, similars als de I'Aptià, que s'han fet palesos anteriorment. Uns i altres pertanyen al Cretàcic Inferior.

En aquest indret hi ha unes mineralitzacions ferruginoses, les quals es troben relacionades amb un "hard-ground" localitzat a la base del Barremià, situant-se per sota de un nivell de les calcàries anteriorment esmentada. Es tracta d'un aflorament important de les denominades argiles laterítiques.

Els minerals presents més abundants són: la CAOLINITA (entre les argiles) i els minerals de ferro i alumini. Cal dir que els de ferro és fan molt més palesos, amb la presencia del mineral HEMATITES i de la roca LIMONITA (constituïda fonamentalment per la GOETHITA i amb presencia de LEPIDOCROCITA i de SIDEROGEL). Per la seva banda, entre els minerals d'alumini, es fan palesos la BOEHMITA, la GIBBSITA i el ALUMOGEL (integrants normalment de la roca BAUXITA). Tanmateix, amb tots els minerals anteriors, també es troba present la CALCITA.

Al respecte de l'aflorament anterior, cal considerar que no es tracta d'una BAUXITA (com s' ha definit de vegades), ni d'una LATERITA (com també s'ha definit, encara que és un terme més proper), sinó d'unes ARGILES LATERÍTIQUES, terme condicionat per la presencia dels minerals argilosos, dels òxids de ferro (laterites i limonites) i pels òxids d'alumini (bauxites). En aquest indret, predominen els de ferro sobre els d'alumini.

Aquesta mineralització va ésser explotada temps enllà, durant el segle passat, a l'igual que altres similars del veí terme de Beseit (comarca del Matarranya) i del de Tortosa (Baix Ebre). (fotografia 2). 


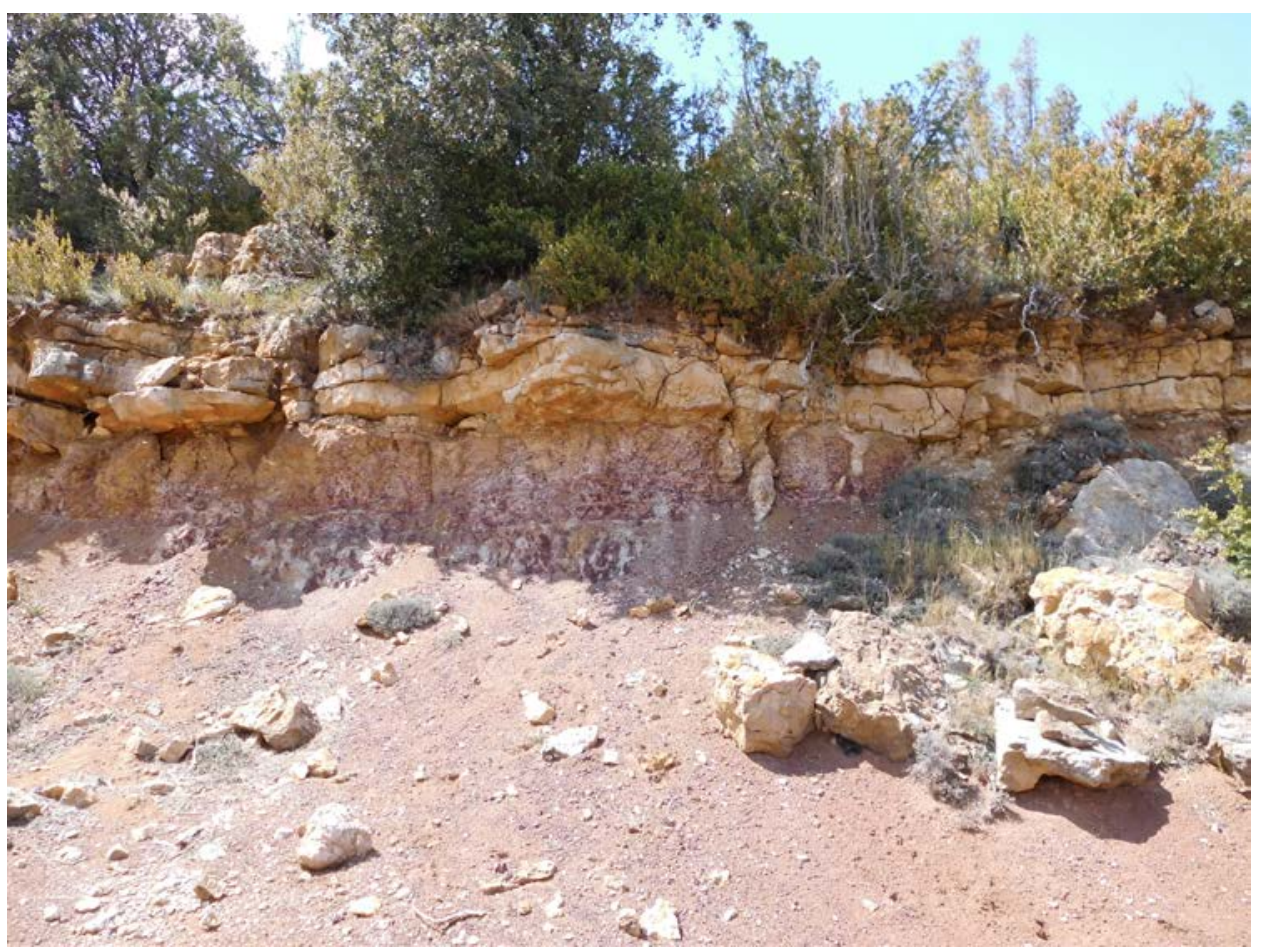

Fotografia 2. Aflorament d'argiles laterítiques

També cal fer esment de que pels voltants d'aquest indret, en una zona eminentment calcària, existeixen nombroses coves i avencs (com la Cova d'en Quixal), com a conseqüència de la intensa activitat kàrstica desenvolupada.

\subsection{Parada 8. CRUÏLLA AMB LA CARRETERA DEL CONVENT DE BENIFASSÀ, (el Bellestar, terme municipal de la Pobla de Benifassà, comarca del Baix Maestrat). (full 521)}

Des de la parada anterior, cal continuar cap al poblet de Fredes. En arribar-hi, ens convindrà seguir per la carretera que va baixant cap a la Sènia. Més avall, en trobar el trencall que es dirigeix cap al proper Convent de Benifassà, podem fer una nova aturada dintre d'aquest itinerari. Així, haurem efectuat un recorregut proper als $17 \mathrm{Km}$, des de l'anterior aturada, uns 10 i pico des de Fredes Aquest darrer recorregut, I'haurem fet seguint la carretera local CV - 106.

En aquest recorregut hem continuat trobant els materials mesozoics esmentats a les aturades anteriors. Inicialment, aquests materials han estat els del Barremià (Cretàcic Inferior). Després, ben aviat, han estat encavalcats pels juràssics del Dogger. Tot i així, hem tornat a trobar els materials carbonatats cretàcics de l'Aptià i del Barremià (precisament, baixant de la Colònia Europa, haurem tornat a trobar uns nivells laterítics, entre aquests darrers materials).

Tot i així, més aviat, hem tornat a trobar afloraments dels materials carbonatats del Juràssic. Malgrat això, més avall, hem tornat a veure afloraments cretàcics de l'Aptià i fins i tot del Barremià. Precisament, ara en aquest indret, es fan palesos uns nivells de l'Albià; concretament en aquest lloc hi ha un aflorament dels materials cretàcics els quals pertanyen a la Formació Escucha. 
Així, en aquest mateix indret, hi ha una antiga explotació d'aquests materials cretàcics, que afloren en aquest indret. Entre els material es troben uns nivells de lignits i de caolins. Ambdós materials van ésser explotats, fa un cert temps.

Entre els lignits, hi ha mineralitzacions ferruginoses secundàries, originades a partir de l'alteració de PIRITA primària. Entre els minerals presents, hi ha sulfurs secundaris de ferro com la MARCASSITA (i) i la MELNIKOWITA (i); també hi ha òxids de ferro com la GOETHITA (terrosa i limonítica, molt abundant), LEPIDOCROÍTA (i) i el SIFEROGEL; i tanmateix també hi ha sulfats de ferro com I'HALOTROIQUITA i MELANTERITA. Ocasionalment, entre els sulfats, també pot haver-hi GUIX, produït a partir de I'Àcid Sulfúric generat en I'oxidació de la PIRITA, en trobar-se en presencia de carbonats de calci, com la CALCITA.

Per altra banda, cal fer esment també de la presència de CAOLINITA, IL.LITA i QUARS, entre els materials argilosos de la Formació Escucha. I, finalment, cal parlar també de la presencia ja esmentada de la CALCITA.

\subsection{Parada 9. CARRETERA DEL BOIXAR A FREDES, MIRADOR DEL TURÓ DE COTA 1.197M, (Boixar, terme municipal de la Pobla de Benifassà, comarca del Baix Maestrat). (full 521)}

Des de la parada anterior cal acabar de baixar per la carretera CV - 106, fins arribar a la cruïlla amb la procedent de la Sènia (la CV - 108). Ara ens caldrà seguir per aquesta, anant cap a ponent, fins a trobar la carretera CV - 105, la qual es dirigeix cap al poble de Boixar. Poc abans d'arribar-hi, es trobarà la carretera que es dirigeix a Fredes, per la qual ens caldrà seguir lleugerament, fent una fillola. En arribar al punt més alt de la mateixa, ens caldrà fer una nova aturada, després d'haver recorregut uns $12 \mathrm{Km}$, des de l'anterior.

En aquest recorregut hem continuat trobant els materials cretàcics ja esmentats a les parades anteriors. Ara aquí, en aquest indret afloren els nivells carbonatats del Cretàcic Inferior, concretament afloren a l'indret aturonat on ara ens trobem situats.

En aquest lloc es pot gaudir d'un immillorable punt d'observació. En efecte, des d'aquí es poden veure, en primer terme els relleus mesozoics de la Tinença, situats dintre de la Branca Externa de la Serralada Prelitoral Catalana, a la seva Zona d'Enllaç.

Més lluny, per sota dels relleus anteriors, es pot veure la Depressió d'Ulldecona, reblerta de terrenys miocènics, pliocènics i quaternaris. Aquesta depressió es troba a la zona esfondrada del denominat Grau de Tortosa-Onda.

També, més lluny i en la mateixa direcció que els relleus i depressions, es poden veure els relleus del Montsià, els quals es troben situats dintre de la Branca Interna de la Serralada Prelitoral Catalana, la qual es troba constituïda per afloraments de materials juràssics $\mathrm{i}$ cretàcics. 


\subsection{Parada 10 - CONDICIONAL. CARRETERA LOCAL CAP A CORATXAR, (antic terme municipal de Boixar, actualment del terme de la Pobla de Benifassà, comarca del Baix Maestrat). (full 520)}

Des de fer l'aturada anterior, cal tornar enrere, cap a la carretera CV - 105, per tal de continuar el recorregut cap a Boixar. En arribar-hi, cal agafar la carretera que va a Coratxar (la CV 109). A uns 2 ' $5 \mathrm{Km}$ del primer poble, cal efectuar la present aturada, per les immediacions del Mas de Colau. Així, des de l'anterior, s'haurà efectuat un recorregut aproximat de prop de 6 $\mathrm{Km}$.

En aquest recorregut, hem continuat trobant afloraments dels materials cretàcics. Tot i així, prop de Boixar, hem tornat a trobar afloraments dels materials carbonatats del Juràssic. Així con nivells argilosos, també juràssics. Així, en aquest indret, hi ha un aflorament dels materials mesozoics de la Fàcies Purberck. Entre els hi ha uns lignits que contenen mineralitzacions ferruginoses. Els minerals presents són: PIRITA, MARCASSITA (i), GOETHITA (en forma de limonita), CALCITA, GUIX i MELANTERITA.

Per altra banda, prop d'on ara som, al Mas de la Roda, hi ha una mineralització ferruginosa, relacionada amb un "hard-ground". Els minerals presents són: GOETHITA, HEMATITES, CALCITA i CAOLINITA. Aquesta mineralització que es situa a la base del Barremià, es similar a la que hem vist a la PARADA 7, d'aquest mateix itinerari.

I, també pels voltants del poble de Coratxar, a la Serra albardes (PARADA 10 -BIS), hi ha una altra mina de lignit, en un aflorament molt semblant al de I'aflorament que hem descrit de la carretera.

\subsection{Parada 11. CARRETERA DE BOIXAR A CASTELL DE CABRES, IMMEDIACIONS DELS KMS. 28’6 AL 29, (terme municipal de Castell de Cabres, comarca del Baix Maestrat). (full 545)}

Des de la parada anterior, cal retornar cap al poble de Boixar, per tal de continuar després cap a ponent, seguint de nou per la carretera CV - 105, per tal d'anar-nos aproximant al poble de Castell de Cabres. Abans d'arribar-hi cal fer la present parada, després de recórrer uns $8 \mathrm{Km}$ més, des de la parada anterior.

En aquest recorregut, hem continuat trobant afloraments dels materials mesozoics (del Juràssic i sobretot del Cretaci) ja esmentats a les parades anteriors. Aquest materials pertanyen a la Serralada Ibèrica, i s'inclouen dintre de la denominada Zona d'Enllaç.

Des d'aquest indret, es poden veure unes interessants estructures, Així, des del pla situat al $\mathrm{Km} \mathrm{28} 6$, i mirant cap al Nord, es pot veure un sinclinal, entre els materials cretàcics.

Respecte d'aquest sinclinal, cal dir que ja el tornarem a veure, des del mateix poble de Castell de Cabres.

Més endavant, des de les immediacions del Km 29 de la carretera, tot mirant cap a l'oest, es poden veure un conjunt de plecs molt interessants entre els materials cretàcics. 


\subsection{Parada 12. ENTRADA A CASTELL DE CABRES, PER LA CARRETERA DE TORRE MIRÓ, CV - 105, (terme municipal de Castell de Cabres, comarca del Baix Maestrat). (full 520)}

Després de fer l'aturada anterior cal seguir cap al proper poble de Castell de Cabres, per la carretera procedent de Boixar, que estem ara seguint, la CV - 105. Així, s'arribarà en uns 4 $\mathrm{Km}$ a l'indret de la present aturada.

En aquest recorregut hem continuat trobant els materials anteriorment esmentats a les parades anteriors. Molt sovint aquests materials eminentment carbonàtics es troben replegats. Així, en arribar a Castell de Cabres, es pot veure un interessant sinclinal sobre el qual es troba situada la població. (fotografia 3).

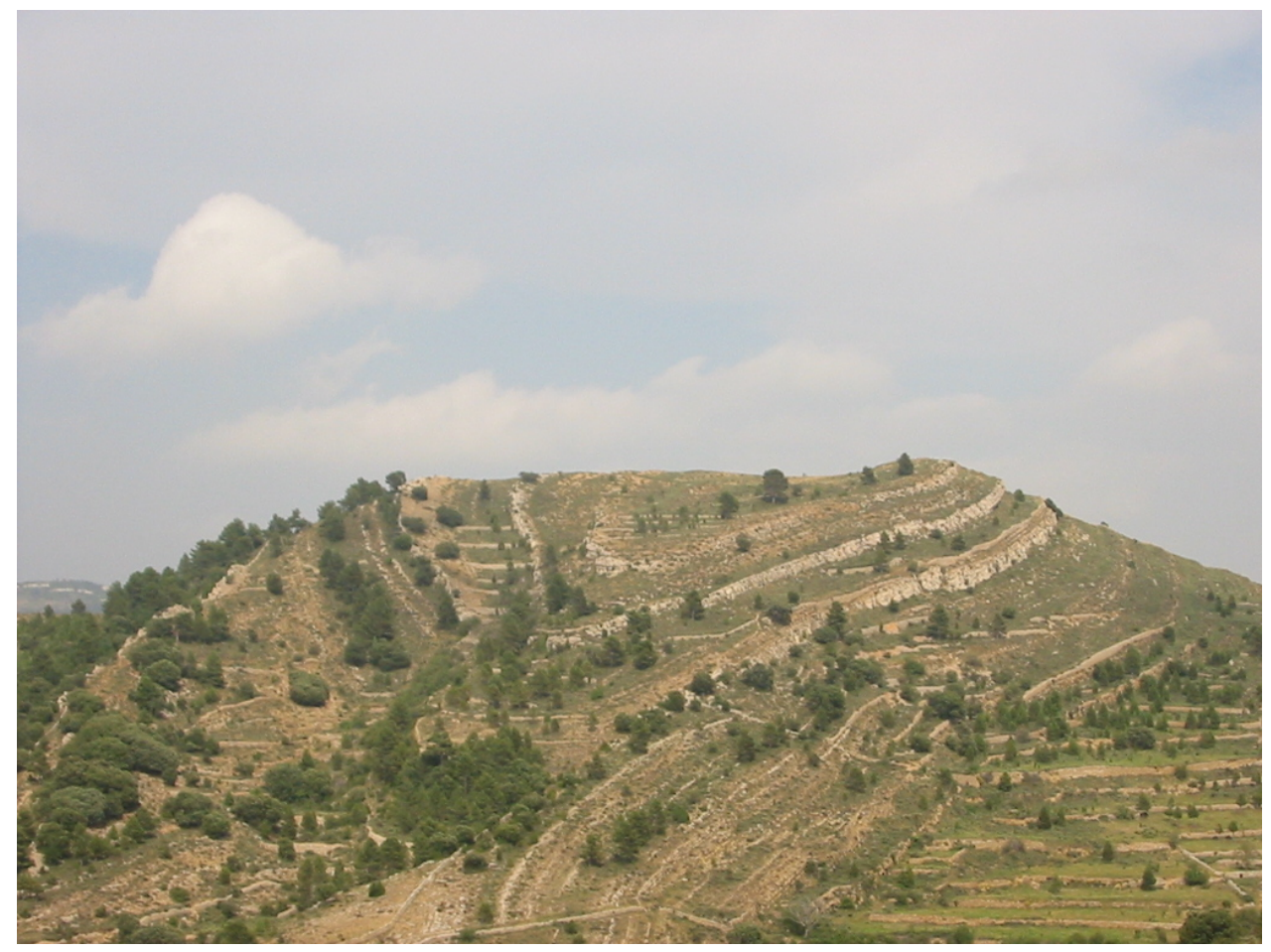

Fotografia 3. Un aspecte del Sinclinal de Castell de Cabres

També, des del mateix poble, mirant cap a llevant, es pot veure la continuació d'aquest sinclinal; precisament a l'anterior aturada, ja l'hem vist, venint des del poble de Boixar.

En aquest indret finalitza el recorregut de l'itinerari 


\section{Bibliografia}

GUIMERÀ, J. et altri /1992).- Geologia (II), Història Natural dels Països Catalans, Vol.2, 547 pag. Enciclopèdia Catalana, S,A, Barcelona.

IGME (1973).- Mapa Geológico de España, a escala 1:50.000, $2^{\text {a }}$ Serie. Full i memória no 546 (Ulldecona). Instituto Tecnológico y GeoMinero de España. Ministerio de Indústria. Madrid.

IGME (1979).- Mapa Geológico de España, a escala 1:50.000, 2ª Serie. Full i memória no 522 (Tortosa). Instituto Tecnológico y GeoMinero de España. Ministerio de Indústria. Madrid.

MATA-PERELLÓ, J.M. (1991).- Els Minerals de Catalunya. Institut d'Estudis Catalans. Arxius de la Secció de Ciències, T.XLVIII, 506 pag. Barcelona.

MATA-PERELLÓ, J.M. (2006a).- Recorregut de recerca geològica i mineralògica per les comarques dels Ports i del Baix Maestrat: des de la Pobla d'Alcolea a Castell de Cabres i a Fredes. Inèdit.10 pàgines. Manresa.

MATA-PERELLÓ, J.M. (2006b).- Recorregut de recerca geològica i mineralògica per les comarques del Baix Maestrat i dels Ports: des de Vallibona, a Torre Miró, Castell de Cabres i a Fredes. Inèdit.10 pàgines. Manresa.

MATA-PERELLÓ, J.M. (2011).- Recorregut de recerca geològica i mineralògica per la comarca del Baix Ebre: des de Roquetes als Reguers i al Mont Caro. Inèdit. 8 pàgines. Manresa.

MATA-PERELLÓ, J.M. (2014).- Recorregut de recerca geològica i mineralògica per la comarca del Baix Ebre: des de Roquetes als Reguers al Caragol i al Mont Caro. Inèdit.10 pàgines. Manresa.

RIBA, O. et altri (1976).- Geografia Física dels Països Catalans. Edit. Ketres, 254 pàgines. Barcelona. 